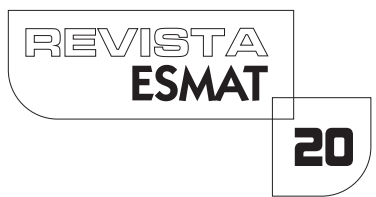

\title{
A EDUCAÇÃO MORAL/CIDADÃ NA PERSPECTIVA DA PREVENÇÃO DA CRIMINALIDADE: PROJETO ÂNCORA
}

\author{
MORAL/CITIZEN EDUCATION IN THE PERSPECTIVE OF CRIME
} PREVENTION: PROJETO ÂNCORA

RÁYLLA BARBOSA ARAÚJO PATRÍCIA MEDINA ${ }^{2}$

\begin{abstract}
RESUMO
O presente estudo possui como tema, escolas inovadoras e a formação moral para prevenção da criminalidade; objetivou compreender o Projeto Âncora, registrando suas peculiaridades, especialmente as relacionadas aos aspectos metodológicos da educação moral, comparando-os às teorias de prevenção da criminalidade. Utilizou-se da pesquisa revisão para obtenção de informações em publicações científicas relacionadas às diversas teorias da criminalidade, nas metodologias de educação moral e nos aspectos metodológicos inovadores encontrados no Projeto Âncora. Concluiu-se que os procedimentos educacionais deste Projeto desenvolvem nos educandos o senso de responsabilidade sobre o andamento das questões sociais e que a práticas pedagógicas proporcionam a internalização das morais sociais, fazendo com que os educandos sejam menos propensos a práticas de atos que transgridem as leis e normas traçadas pelo estado.
\end{abstract}

PALAVRAS-CHAVE : Teorias Criminológicas. Jean Piaget. Métodos Ativos.

\begin{abstract}
This study has as its theme, innovative schools and moral education for crime prevention, aimed at understanding Projeto Âncora by recording its peculiarities, especially those related to the methodological aspects of moral education, comparing them to crime prevention theories. The review research was used to obtain information in scientific publications related to the various theories of crime, the variables of moral education methodology and innovative methodological aspects found in Projeto Âncora. It was concluded that the educational procedures of Projeto Âncora develop in the students a sense of responsibility about the progress of social issues and that pedagogical practices provide the internalization of social morals, making the students less prone to practice so facts that violate the laws and norms outlined by the state.
\end{abstract}

KEYWORDS: Criminological Theories. Jean Piaget. Active Methods.

\footnotetext{
1 Pedagoga (UFT-Palmas), professora da educação infantil e dos anos iniciais do ensino fundamental. araujoraylla24@gmail.com

${ }^{2}$ Doutora e mestra em Educação. Pedagoga e bacharel em Direito. Professora Associada da Universidade Federal do Tocantins nos cursos de Pedagogia e Mestrado em Prestação Jurisdicional e Direitos Humanos (UFT-Esmat).patriciamedina@uft.edu.br
} 


\section{INTRODUÇÃO}

O crime caracteriza-se pela ação ou ato, em que um indivíduo que está inserido em dada sociedade descumpre as regras e leis que a regem. No Brasil, o aumento da criminalidade tem alarmado a população e o Estado, fazendo com que os debates acerca do tema tenham destaque na mídia e nas redes sociais.

A criminalidade vem sendo debatida principalmente no que tange à maioridade penal. Para uma grande parcela da população brasileira a maioridade penal deve ser reduzida de 18 para 16 anos; porém, essas discussões raramente tratam da prevenção do ato criminoso. Vê-se, nesse ponto, a necessidade de se discutirem as formas de prevenção da criminalidade, antes de planejar punições para os atos criminosos. Com relação a isso, esta pesquisa tem como foco a criminalidade e as suas possíveis formas de prevenção.

A Constituição Federal (BRASIL, 1988) brasileira define como função da educação promover e incentivar o pleno desenvolvimento dos seus indivíduos, preparando-os para o exercício da cidadania e qualificando-os para o trabalho. Exercer a cidadania é atuar em sociedade estando consciente de seus deveres e direitos, pelo que é justo e correto, procurando formas de colocá-los em prática; portanto, é papel de o cidadão cumprir as leis (não cometer crimes), respeitar os direitos sociais de outras pessoas, educar e proteger os semelhantes.

Se o papel do cidadão é cumprir as leis, é, então, papel da educação conscientizar os educandos da necessidade de seguirem as regras estabelecidas pela sociedade. Afirma-se, a partir disso, que é função da educação promover a prevenção da criminalidade.

Durante pesquisas sobre escolas inovadoras, tomou-se conhecimento da existência do Projeto Âncora, escola cujas ações educativas fogem da metodologia tradicional. Devido à diferença metodológica adotada, o Projeto Âncora foi escolhido para demonstrar possíveis caminhos formadores de cidadãos e, por conseqüência, a prevenção da criminalidade. Portanto, busca-se, neste artigo, registrar as reflexões que resultaram da pergunta problema de pesquisa: Como a prática pedagógica do Projeto Âncora contribui para a educação moral e cidadã da criança, na perspectiva da prevenção da criminalidade?

O objetivo da pesquisa foi conhecer o Projeto Âncora a partir das produções acadêmicas e jornalísticas, registrando suas peculiaridades que estão relacionadas aos aspectos metodológicos da educação moral, comparando-os às teorias de prevenção da criminalidade. O primeiro passo, para alcançar o objetivo da pesquisa, foi descrever as principais teorias da criminalidade. O segundo, descrever as principais teorias relacionadas 
à educação moral. E o terceiro, analisar as práticas pedagógicas do Projeto Âncora à luz das teorias de educação moral e das principais teorias da criminalidade.

Diante do aumento da criminalidade, a sociedade vem se envolvendo cada vez mais num manto de medo e de ódio. Medo de ter seus bens materiais roubados e/ou destruídos, ou até mesmo de suas vidas serem tiradas, e ódio daqueles que praticam esses tipos de atos. O ódio leva as pessoas a quererem aquilo que odeiam o mais longe possível, isso faz com que as manifestações, na sociedade, por aumento da maioridade penal, por prisões perpétuas e penas de morte, aumentem cada vez mais. Logo, os espaços de discussões de prevenção da criminalidade passam a se tornar locais de discussões sobre medidas punitivas, com o pretexto de que o medo fará com que os infratores desistam de praticar atos ilícitos. É preciso conscientizar a sociedade de que é mais lucrativo prevenir a criminalidade de que puni-la. Para tanto, a proposta desta pesquisa é apresentar definições, conceitos e algumas das ferramentas que podem ser utilizadas na conscientização da nossa sociedade e na prevenção da criminalidade.

Esta pesquisa baseou-se em publicações científicas relacionadas às diversas teorias da criminalidade, nas variáveis metodologias de educação moral e nos aspectos metodológicos inovadores encontrados no Projeto Âncora. Para a compreensão dos conteúdos, foram feitos fichamentos dos livros, artigos, notícias e vídeos assistidos.

Este artigo divide-se em três partes: na primeira, a história e as perspectivas sociológicas dadas à criminalidade, e as teorias dos consensuais e conflituais do crime, além dos tipos de prevenção. A segunda apresenta as diversas teorias da educação moral, com foco na perspectiva piagetiana, relacionando-a também à cidadania. Por fim, são apresentadas as metodologias adotadas nas práticas pedagógicas do Projeto Âncora, procurando demonstrar como suas práticas de educação moral podem contribuir para a prevenção da criminalidade.

\section{VISÃO GERAL SOBRE A CRIMINALIDADE}

Quebrar as regras de determinado grupo ou sociedade tem sido um fato promotor de grandes mudanças nas sociedades. Um ato se só torna criminoso quando ofende os fortes sentimentos compartilhados por membros de um grupo social, e em todas as sociedades a característica comum é a de que os atos considerados criminosos são altamente repudiados pelos componentes da sociedade (DURKHEIM, 1999). 
Trata-se de um ato de ofensa a consciência coletiva de determinada sociedade, sendo este passível de punição. $\mathrm{O}$ crime agita de forma negativa os sentimentos da sociedade. Essa agitação produz emoções violentas, criadoras de novas percepções que podem ser afirmativas ou contrárias aos ideais já estabelecidos em nossa psiquê. Essa agitação é o que proporciona mutabilidade das relações/percepções culturais (DURKHEIM, 1999).

No Brasil, os atos criminosos têm crescido assustadoramente; em 2017, o País alcançou números nunca registrados, principalmente no que tange ao índice de homicídios. Segundo o Fórum Brasileiro de Segurança Pública (2018), em 2017 ocorreram 63.895 mortes violentas intencionais, cerca de 180 mortes por dia, o que corresponde a uma média de 30,8 mortes para cada 100.000 habitantes; neste mesmo ano, foram registrados 262.353 roubos e furtos de veículos, o número de roubos registrados a estabelecimentos comerciais foi de 79.279 e de 42.761 roubos a residências. O número de roubos a pessoas que se deslocavam a pé (transeuntes) foi de 735.787, já o número de roubos a instituições financeiras foi de 906; por fim, em 2017 foram registrados 24.941 roubos de carga. O total de furtos e roubos registrados em 2017 foi de 1.703.872. A respeito do número de adolescentes envolvidos em conflito com a lei, em 2016, havia 26.450 deles cumprindo medidas socioeducativas.

Pode-se dizer que o crime tem sido um fator prejudicial à vida em sociedade. Para Dornelles (2017), a classificação de uma ação como um ato criminoso, ou não, pode variar numa mesma sociedade, o autor deixa claro que, de acordo com os tempos e espaços de uma sociedade, vão mudando as perspectivas socioculturais daquela sociedade, fazendo com que as noções do que sejam, ou não, crimes também se modifiquem. Um exemplo de como uma sociedade pode mudar suas percepções do que seja, ou não, um crime é o caso das mulheres que são presas por terem abortado no país de El Salvador, localizado na América do Norte. Até 1998, o aborto nesse país era permitido em três casos: o de estupro, o risco representado à vida da mãe e a inviabilidade do feto; no entanto, após uma mudança na legislação desse país, o aborto passou a ser irremediavelmente proibido; independentemente de como ocorresse (até mesmo aborto involuntário), a mulher seria indiciada pelo crime de homicídio agravado, sendo punida com pena de 30 a 50 anos de detenção (ÀlLVAREZ, 2019).

Nesse contexto, fica claro que a consciência coletiva é quem determina se algo é bom ou mau. $\mathrm{O}$ mais preocupante é constatar que às vezes um crime não recebe punição justa. Não é exagero afirmar que as punições direcionadas aos crimes "consistem numa 
reação passional" (DURKHEIM, 1999, p.56), cuja aplicação algumas vezes ocorre pelo simples prazer de punir, noutras, como método de proteção, com a pretensão de que a imposição de um castigo (pena) provoque um temor capaz de paralisar as más intenções do indivíduo. Conforme Dornelles (2017), é importante afirmar que o crime não é apenas um ato anormal, e sim uma ação que não se enquadra nas normas sociais, sejam elas jurídicas ou simplesmente morais, ou seja, sejam elas passíveis de pena ou somente de repreensões sociais.

O crime está presente em todas as sociedades, pois é uma ação que desrespeita as normas sociais, sejam elas jurídicas ou morais. O crime possui a capacidade de modificar a sociedade levantando questões que até então não eram abertamente discutidas. Porém, quando se trata de crimes, como assassinatos, roubos, estupros, etc., o ônus para a sociedade em que estes ocorrem é de um valor imensurável, portanto, surge a necessidade de se discutirem o aumento da criminalidade e as formas de prevenção desses atos.

Com relação às normas, Durkheim afirma que

[...] o crime só é possível se esse respeito não for verdadeiramente universal [...]. Portanto, se quando um crime se produz, as consciências que ele ofende não se unissem para atestar que essa permanece em comunhão [...] elas não poderiam deixar de ser abaladas a longo prazo. Mas é preciso que elas se reconfortem, garantindo-se mutuamente que estão sempre em uníssono; o único meio para isso é reagirem em comum. Numa palavra, já que é a consciência comum que é atingida, cumpre também que seja ela que resista e que, por conseguinte, a resistência seja coletiva. (DURKHEIM, 1999, p. 76).

Ou seja, quando uma sociedade tem as normas infringidas, precisa se unir para afirmar que a transgressão ocorrida é um fato anormal, isolado e inaceitável, senão esta norma correrá o risco de ser abalada e consequentemente esquecida. Esse é o motivo pelo qual é importante discutir o aumento dos atos criminosos, procurando principalmente formas de preveni-los, com a intenção de evidenciar aos cidadãos que esses tipos de atos devem ser considerados anormais, e inaceitáveis. Porém, é necessário também entender o que direciona os indivíduos de certa sociedade a romper com as normas por ela expostas; por isso, trataremos a seguir de algumas das teorias do crime.

\subsection{Teorias criminológicas consensuais}

Criminologia é o estudo das causas do comportamento antissocial, com base na psicologia e na sociologia. As teorias criminológicas consensuais são de caráter funcionalista; para elas, a sociedade só consegue funcionar corretamente se os seus órgãos estiverem em perfeita sintonia com os seus cidadãos, estando estes focados em atingir objetivos comuns a todos, compartilhando e honrando as regras de convívio. Sendo assim, 
"As teorias consensuais partem dos seguintes postulados: toda sociedade é composta de elementos perenes, integrados, funcionais, estáveis, que se baseiam no consenso entre seus integrantes" (PENTEADO FILHO, 2018, n.p).

Para Calhau (2009), são teorias de consenso: a da subcultura delinqüente; a da associação diferencial; a da Escola de Chicago; e a da anomia. A teoria da subcultura delinquente, de modo sintético, defende que a conduta delitiva é a personificação de valores e normas que estão aparentes em sistemas subculturais (categorias de pessoas e sistemas sociais que integram grupos maiores); neste caso, a conduta delitiva ocorre quando o indivíduo aceita regras e valores de determinado grupo, colocando-o acima das normas e valores sociais dominantes. Para a teoria da associação diferencial, o comportamento desviante é resultado de um aprendizado, ou seja, não se nasce criminoso; porém, a relações sociais individuais proporcionam ao indivíduo oportunidades e técnicas de como aproveitar as oportunidades que possui para cometer atos irregulares; segundo a teoria, nas sociedades pluralistas o conflito de valores é peculiar ao sistema; sendo assim, cada indivíduo, sendo influenciado por suas relações sociais, responde às normas legais de formas diferentes. A Escola de Chicago conceitua a delinquência partindo principalmente da relação entre a criminalidade, a forma com que o espaço urbano está organizado; derivada desta escola, a teoria ecológica vale-se essencialmente dos conceitos de contágio e desorganização concernentes aos centros urbanos, evidenciando a falta de controle destes centros. Segundo a teoria da anomia, a falta de sucesso em alcançar os objetivos culturais, causados pela ineficiência do Estado pode gerar um comportamento em que o indivíduo abandona ou deixa de lado as regras do convívio social, realizando então ações desviantes (CALHAU, 2009).

De acordo com Penteado Filho,

As teorias de consenso entendem que os objetivos da sociedade são atingidos quando há o funcionamento perfeito de suas instituições, com os indivíduos convivendo e compartilhando as metas sociais comuns, concordando com as regras de convívio. [...] Aqui os sistemas sociais dependem da voluntariedade de pessoas e instituições, que dividem os mesmos valores (PENTEADO FILHO, 2018, n.p)

Pode-se dizer que as teorias do consenso se baseiam na colaboração entre as instituições e as pessoas, tendo de compartilhar os mesmos valores sociais; portanto, as relações se dariam entre iguais. Nesse contexto, fica claro que na teoria consensual não há espaço para diferenças e muito menos para mudanças (PENTEADO FILHO, 2018). Essas teorias se baseiam na busca pela igualdade de pensamentos, de valores e de objetivos de uma sociedade. Portanto, para essa linha teórica, um ato criminoso é sempre um ato em que 
o indivíduo se desvia dos objetivos comuns da sociedade deixando de compartilhar/concordar com os valores dela.

\subsection{Teorias criminológicas conflituais}

As teorias criminológicas conflitais são teorias de caráter argumentativo. Para as teorias derivadas dessa corrente, a estabilidade das sociedades só ocorre devido aos sistemas de poder que perpetuam as relações entre dominantes e dominados, por meio da força e da coerção. Nessa situação, "não existe voluntariedade entre os personagens para a pacificação social, mas esta é decorrente da imposição ou coerção" (PENTEADO FILHO, 2018, n.p).

Ainda segundo Calhau (2009), são consideradas teorias conflitais a Labelling Approach e a crítica ou radical. A teoria Labelling Approach, também conhecida como teoria do etiquetamento, rotulação ou reação social, tem sido destacada como um marco nas teorias de conflito, por centrar-se na reação da sociedade mediante a ocorrência de um delito. Para ela, os desvios só existem porque a sociedade determinou que somente tais caminhos pudessem ser seguidos, qualificando as pessoas que seguissem outros caminhos, além dos que lhes foram determinados, como marginais. Sendo assim, o delito é somente uma etiqueta produzida por uma parte privilegiada da sociedade que determina quem é o quê. A teoria crítica ou radical ficou marcada como uma criminologia marxista, cujo entendimento do que é delito partia principalmente da concepção de que este estava unicamente associado ao modo de produção capitalista (CALHAU, 2009).

De acordo com Penteado Filho,

[...] as teorias de conflito argumentam que a harmonia social decorre da força e da coerção, em que há uma relação entre dominantes e dominados. Neste caso, não existe voluntariedade entre os personagens para a pacificação social, mas é decorrente da imposição ou coerção. [...] Os postulados das teorias de conflito são: sujeitas a mudanças contínuas, sendo ubíquas, de modo que todo elemento coopera para a sua dissolução [...]. Haveria sempre uma luta de classes ou de ideologias [...] (PENTEADO FILHO, 2018, n.p, grifo do autor).

As teorias conflituais têm como foco as divisões sociais e os processos de empoderamento e descriminação, ocasionados pelas relações de poder, oriundas do modelo capitalista de sociedade. Nesse contexto, fica claro que o foco das teorias conflituais é inteiramente contrário ao das teorias consensuais, pois para eles as sociedades estão sempre suscetíveis a mudanças (PENTEADO FILHO, 2018).

As teorias conflituais criminológicas se apoiam nos questionamentos sobre as relações de poder existentes nas sociedades. Portanto, um ato só é considerado criminoso 
quando um grupo que detém o poder determinasse que aquele ato seria, a partir daquele momento, considerado irregular. Dessa forma, a uniformidade social não é mantida por meio de objetivos/valores comuns à sociedade, mas sim pela força da imposição e da coerção que uns grupos exercem sobre outros.

\title{
2.3 A prevenção da infração penal .
}

Apesar de o crime ser um fato social, é de extrema importância para a sociedade prevenir essa ação. O conceito de prevenção do crime possui diferentes vertentes, para alguns autores, prevenir o crime é fazer com que o delinquente desista de cometer o ato ilícito; para outros, é mais que isso, é também "modificar espaços físicos, novos desenhos arquitetônicos, aumento da iluminação pública com o intuito de dificultar a prática do crime" (CALHAU, 2009, p. 91), já um terceiro grupo entende que prevenir o crime é somente impedir a reincidência.

É possível verificar, por exemplo, que a prevenção primária defende investimentos na qualidade de serviços, como educação, emprego, segurança, moradia e cultura por parte do Estado, ou seja, propõe maneiras de fazer com que o indivíduo não cometa nenhum ato ilícito. A prevenção secundária opera em ambientes onde ocorrem mais crimes; portanto, a prevenção secundária se dá somente quando há crime, de forma a evitar que ele se multiplique, por meio da repressão policial. Já a prevenção terciária ocorre depois que o delito foi cometido, e o autor do crime já está cumprindo pena. Esse modelo de prevenção tem como foco promover a reabilitação do infrator, com o intuito de evitar uma possível reincidência (CALHAU, 2009; PENTEADO FILHO, 2018).

A respeito da finalidade preventiva da pena, Galvão afirma:

\begin{abstract}
A finalidade da preventiva da pena pressupõe que seja possível realizar um prognóstico, suficientemente seguro, do comportamento humano futuro e, ainda, que a característica socio-pedagógica da pena possa combater, com eficácia, a tendência criminosa dos indivíduos. Da mesma forma que a ideia de retribuição, a finalidade da intimidação ou prevenção labora com o princípio de que os valores socialmente dominantes são moralmente legítimos e, nesse ponto, pode-se encontrar premissa comum entre as idéias de retribuição e prevenção (GALVÃO, 2007, p. 17)
\end{abstract}

Logo, a função preventiva da pena se baseia nas possibilidades futuras do comportamento do criminoso, partindo da concepção de que os valores dominantes devem ser aceitos por todos. Nesse contexto, fica claro que "a prevenção pode manifestar-se em uma perspectiva especial ou geral considerando-se a possibilidade de evitar a ocorrência de novos crimes e a amplitude de seus destinatários" (GALVÃO, 2007, p. 17). 


\section{A MORAL}

A moral é um grupo de deveres que correspondem à filosofia dominante de certa sociedade, sendo possível dividi-la em três classes: regras, princípios e valores. Nesse contexto, a moral é a implicação das regras da sociedade; portanto, o bom cidadão é aquele que observa e pratica os princípios e as regras da sociedade em que está situado, ou seja, é aquele que segue a moral social (LA TAILLE, 2006).

Pode-se dizer que, para Durkheim (2017), o ser moral é aquele que acata os ideais da sociedade em que está inserido. Segundo ele, é necessário que se estabeleça o sentimento do sagrado, seja por meio do medo de sofrer punições de um ser superior ou pela simples vontade de ser um indivíduo de qualidades notadamente apreciáveis e indispensáveis.

Um bom cidadão atende integralmente às regras e aos valores a ele impostos. Nesse caso, a moral é simplesmente heteronômica, pois deriva somente da vontade e das concepções do outro, no caso, da consciência coletiva, e não do indivíduo que a recebe. Para Durkheim (2017), o sistema moral já está pronto e cabe ao cidadão adaptar-se a ele; assim, antes de ter em si o sentimento do sagrado, a criança encontra-se numa fase prémoral e somente ao adquirir esse sentimento ela será um ser moral.

É interessante, aliás, compreender também que, para Piaget (1994), a criança possui duas morais, a primeira é a heterônoma, a qual se caracteriza pelo respeito total às normas determinadas pelos pais, grupos e pela sociedade. A segunda é a moral autônoma, adquirida somente quando o indivíduo deixa de acreditar cegamente nas normas a ele impostas e passa a pensá-las a partir de uma análise crítica delas mesmas; para tanto, o autor deixa claro que essa superação só pode ocorrer se houver relação de respeito mútuo.

As concepções de Piaget e Durkheim se complementam. A teoria de Durkheim sobre a moral finaliza-se ao dizer que ela se dá de forma heterônoma; já a teoria piagetiana afirma que além da moral heterônoma existe também a moral autônoma. Nesses casos, quando a moral está baseada na coação "a heteronomia [...] sai reforçada. Em compensação, se o convívio social permitir relações simétricas de cooperação [...] a autonomia moral torna-se possível" (LA TAILLE, 2006, p.16).

Moral é um sistema de regras que possui como função promover a harmonia da população, fazendo com os indivíduos compartilhem dos mesmos deveres, valores e princípios. Assim, um bom cidadão é aquele que está moralmente apoiado nas determinações da sua sociedade. 
A respeito da moral, La Taille afirma:

\begin{abstract}
A moral é, antes de mais nada, um objeto de conhecimento. Ela "diz" coisas que a pessoa deve conhecer. Mas o que ela diz? Ela fala em regras, e assim diz o que deve ser feito e o que não deve ser feito. Ela fala em princípios, ou em máximas, e portanto, diz em nome do que as regras devem ser seguidas. E ela fala em valores, e assim revela que investimentos afetivos são derivados os princípios (LA TAILLE, 2006, p.73).
\end{abstract}

Logo, a moral é um objeto de conhecimento. Ela deve ser analisada em todos os seus aspectos, e somente com a reflexão sobre todos os seus preceitos é que um indivíduo pode obter uma moral autônoma. Sendo assim, esta só é possível se o indivíduo for capaz de fazer a relação entre as regras, os princípios e os valores, entendendo como um leva ao outro (LA TAILLE, 2006).

A moral social é o regulador da sociedade, ela possui como função promover um equilíbrio dos ideais de determinado grupo, estabelecendo assim uma unidade. Dessa forma, os objetivos e as metas daquele grupo possuem mais chances de serem alcançados. Quando a sociedade reflete sobre suas morais é possível que ela tome dois caminhos, o primeiro é reconhecer a veracidade e a importância de tais regras, buscar, portanto, meios de reafirmá-las; o segundo caminho é compreender que tais normas não se adaptam mais às necessidades de tal sociedade, e, portanto, torna-se necessário buscar meios de substituí-la por algo que atenda de forma eficiente à comunidade.

\title{
3.1 Os conteúdos morais
}

A moral define os deveres de um indivíduo, para que ele possa tornar legítima a sua felicidade perante a sociedade. Porém, a moral, além de dar ao indivíduo deveres que o beneficiam, estabelece principalmente deveres para com os outros. Seguindo essa perspectiva, torna-se necessário compreender quais são os principais deveres que legitimam a felicidade do indivíduo perante a sociedade, ou seja, é preciso conhecer os principais conteúdos da moral (LA TAILLE, 2006).

Na visão de La Taille (2006), as virtudes morais necessárias à busca da felicidade são a justiça, a generosidade e a honra. Para o autor, essas virtudes explicitam o imperativo de que todo ser humano possui valor, e que este deve ser estritamente preservado. Sobre a justiça, afirma que esta é a mais racional das virtudes, pois está baseada nos princípios de igualdade e equidade. Já a generosidade aparece destacada por ser uma virtude altruísta por excelência, pois consiste em compartilhar, em dar ao outro o que ele precisa, com o simples intuito de favorecê-lo. O autor destaca ainda a honra, por estar baseada no valor moral que 
o indivíduo dá a si mesmo, e as ações que este faz, para que o valor que ele reconhece em si também seja reconhecido e respeitado pelo outro.

Logo, se os principais conteúdos da moral forem as virtudes da justiça, da generosidade e da honra, um indivíduo que não é justo, generoso, nem honrado, não pode ter sua felicidade considerada legítima, porque provavelmente pratica ações que não beneficiam outras pessoas além de si mesmo. Nesse caso, o indivíduo não dá o devido valor às outras pessoas, e acabaria cometendo atos imorais, ou seja, atos que a sociedade considera impraticáveis.

A respeito da escolha das três virtudes citadas anteriormente, La Taille afirma:

[...] Três são as virtudes morais que escolho: a justiça, a generosidade, e a honra, todas elas condicionadas pelo imperativo kantiano já citado: cada ser humano deve sempre tratar a humanidade, em outrem e em si próprio, como um fim e nunca como meio. A premissa desse imperativo é que existe uma dignidade inerente a cada ser humano e que ela deve ser estritamente respeitada (LA TAILLE, 2006, p. 61).

O que importa, portanto, é que o indivíduo seja capaz de respeitar as capacidades e as necessidades do outro. Tarefa esta que a sociedade ainda não conseguiu cumprir. Vê-se, pois, que alcançar uma moral plena é um trabalho árduo, que precisa da atenção das instituições sociais. É preciso ressaltar que as virtudes da justiça, da generosidade e da honra são apenas algumas das virtudes necessárias à moral; infelizmente essas virtudes não estão inseridas na vida da maioria dos indivíduos de nossa sociedade; por este motivo, torna-se necessário que a escola, por ser o local dedicado ao desenvolvimento pleno da pessoa e por prepará-la para o exercício da cidadania, procure meios de trabalhar a moral com seus educandos.

\subsection{A educação moral}

A educação moral destina-se a ensinar aos educandos as regras sociais, de forma que os faça ter consciência dela e tomá-las para si, construindo indivíduos autônomos, sempre dispostos a cooperar para a evolução da sociedade. Nessa perspectiva, podem existir dois tipos de morais nas crianças, as quais sequenciam uma à outra quando se permite a evolução moral da criança. A primeira moral que se manifesta na criança é a heterônoma, que deriva da coação e do respeito unilateral; a segunda é a autônoma, que parte do princípio de cooperação e de respeito mútuo. Para Piaget (1996), a moral autônoma destaca-se sobre a moral heteronômica, porque permite que o educando absorva e recrie as morais de sua sociedade a partir de sua própria experiência, fazendo-o, assim, valorizar mais as regras de sua sociedade e cumpri-las de maneira mais efetiva. 
Pode-se dizer que, para Piaget (1996), o respeito mútuo, implica uma relação de cooperação, resultando, assim, na reciprocidade; e somente essa relação é capaz de promover uma real transformação no comportamento moral da criança. Nesse contexto, fica claro que, para o autor, as melhores possibilidades para uma educação moral autônoma ocorram por meio do autogoverno, que é encontrado principalmente em escolas de métodos ativos, nas quais os conteúdos não são impostos à criança, mas por ela são descobertos de forma espontânea, a partir de suas próprias experiências, realizadas principalmente de forma coletiva. Segundo o autor, esses métodos desenvolvem a disciplina, a solidariedade e a responsabilidade ao colocar as crianças como protagonistas do seu aprendizado, pois as expõem a situações semelhantes às da sociedade real, fazendo com que compreendam as relações e os papéis existentes em sua sociedade. Com relação à representação da sociedade, o autor evidencia ainda que os métodos do autogoverno vão desde a oportunidade dada à criança de avaliar e julgar as ações das outras crianças por meio de assembleias, até a de elaborar as normas escolares e executar as ações necessárias para a manutenção da escola.

A educação moral deve promover a formação do caráter, do cultivo da bondade, da verdade, da objetividade, da educação das tendências instintivas (fortalecendo a confiança da criança em si mesma, focando na educação do caráter), da responsabilidade, da justiça, da educação cívica, social e internacional (PIAGET, 1996). Assim, a educação da responsabilidade e da justiça podem se dar a partir dos métodos em que é dado à criança o poder legislativo, judiciário e executivo da unidade escolar; vale ressaltar que, nesses casos, o professor é um mediador que atua somente quando há extrema necessidade de intervenção ou quando a ajuda é solicitada pela criança.

A respeito de suas concepções, Piaget afirma:

Então é evidente que nem a autoridade do professor nem as melhores lições que ele possa dar sobre o assunto serão o bastante para determinar essas relações intensas, fundamentadas ao mesmo tempo na autonomia e na reciprocidade. Unicamente a vida social entre os próprios alunos, isto é, um autogoverno levado tão longe quanto possível e paralelo ao trabalho intelectual comum, poderá conduzir a esse duplo desenvolvimento de personalidades donas de si mesmas e de seu respeito mútuo (PIAGET, 2015, p. 101).

Por fim, podemos chegar à conclusão de que a educação moral autônoma objetiva a formação da criança, nas questões sociais da sociedade em que ela vive, por meio do respeito mútuo, gerando, como conseqüência, a reciprocidade, gerando, assim, indivíduos que estejam dispostos a cooperar para a evolução da sua sociedade, assim como também para o aperfeiçoamento da humanidade. Logo, é indiscutível que a educação moral, quando 
baseada nas propostas para a criação de um indivíduo de moral autônoma, prepara a criança para exercer sua cidadania, cumprindo com os acordos feitos em sociedade que priorizam a evolução desta. Nesse sentido, é possível compreender que a educação moral pode se tornar uma grande aliada na prevenção da criminalidade, pois, quando ensinada por meio de métodos ativos, possibilita ao educando compreender, absorver e buscar resolver as reais necessidades de seu grupo social. Dessa forma, torna possível a diminuição das chances de que a criança venha a praticar de atos que sejam prejudiciais tanto para si quanto para os outros indivíduos de sua sociedade.

\section{O PROJETO ÂNCORA}

O Projeto Âncora é uma instituição de ensino filantrópica, beneficente, educativa e cultural, fundada em 23 de setembro de 1995, localizada na cidade de Cotia, estado de São Paulo. O projeto foi fundado por Walter Steurer e Regina Machado Steurer, com o objetivo de proporcionar um espaço de aprendizagem no qual se evidenciassem as atividades educativas práticas e promovessem a cidadania. Inicialmente o projeto destinava-se a atender a crianças no contraturno das atividades escolares, mas com o passar do tempo foram ficando evidentes as necessidades de oferecer mais que um reforço escolar (PROJETO ÂNCORA, 2019a).

O projeto iniciou com uma simples ação social, mas, em 2002, passou a promover ações que o aproximavam mais das escolas públicas. Algumas das ações realizadas foram a criação de uma biblioteca e o oferecimento de aulas de reforço para as crianças da região. Em 2007, o Âncora passou a promover encontros de educação, com a intenção de ajudar na formação continuada de professores e estudantes de pedagogia (PROJETO ÂNCORA, 2019a).

Após a morte de Walter Staurer, em 2011, o Projeto Âncora decide atender ainda mais às necessidades das crianças acolhidas, surgiu então a ideia de abrir uma escola que atendesse às crianças em tempo integral. A formulação e a implantação da escola contaram com a ajuda do professor José Pacheco, um dos fundadores da Escola da Ponte de Portugal (PROJETO ÂNCORA, 2019a).

De acordo com o Estatuto Social do Projeto Âncora:

Art. $3^{\circ}$. O Projeto Âncora tem por fim contribuir para o desenvolvimento e disseminação de uma cultura de participação social no Brasil, com atuação focada na criança, no adolescente e idoso. 
$\S \mathbf{1}^{\circ}$. Em suas atividades, o Projeto Âncora observará o princípio da universalidade do atendimento, sendo-lhe vedado dirigir suas atividades exclusivamente aos associados ou seus dependentes.

$\S 2^{\circ}$. Para atingir seu objetivo o Projeto Âncora poderá promover, gratuitamente:

a) a proteção da família, à infầncia, à maternidade, à adolescência e à velhice;

b) ações visando à integração das pessoas assistidas pelo Projeto Âncora ao mercado de trabalho:

c) serviços de convivência e fortalecimento de vínculos a pessoas e famílias e situação de vulnerabilidade social de baixa complexidade, sem descriminação de qualquer natureza:

d) o desenvolvimento de projetos e de atividades culturais, educacionais, artísticas e desportivas;

e) o desenvolvimento de atividades complementares àquelas previstas nos incisos acima e orientadas a promover a finalidade do Projeto Âncora. (PROJETO ÂNCORA, 2016, p. 1).

Pode-se perceber o compromisso do Projeto Âncora com a formação e o cuidado com os componentes da sociedade, independentemente da idade ou da situação econômica. O projeto atendeu, em 2019, cerca de 160 crianças, oferecendo educação nos mais diversos níveis, desde a Educação Infantil, os Anos Iniciais e Finais do Ensino Fundamental, até o Ensino Médio, implantado no projeto em 2017. A arquitetura do projeto conta com um espaço de $12.000 \mathrm{~m}^{2}$ compostos por áreas verdes, árvores frutíferas e o Circo Escola, em que são oferecidas oficinas de circo, mosaico, artes plásticas, esportes, música, sustentabilidade, dança, cidadania, culinária e diversos outros (PROJETO ÂNCORA, 2019b).

Os acontecimentos mais marcantes da história do projeto foram: i) 1994, os idealizadores do projeto viajam pelo Brasil buscando tecnologias sociais para fundação de um projeto social e iniciam as obras; ii) 1995, constrói-se o Âncora para que, em 23 de setembro, aconteça o despertar da primavera, coroando a inauguração do Âncora; iii) 1996, sobe-se a lona e inaugura-se a quadra; iv) 2003, Inauguração do CEC; v) 2007, inauguração do Porto do Saber; vi) 2010, ocorrem os encontros de educação com José Pacheco e a festa de 15 anos do projeto; vii) 2011, morre Walter Steurer; viii) 2012, Inauguração da Escola; ix) 2014, surgem as comunidades de aprendizagem; x) 2017, início do Ensino Médio; xi) 2018, reconhecimento do projeto como Ponto de Cultura (PROJETO ÂNCORA, 2019a).

\subsection{Projeto Âncora e suas práticas educativas}

O Projeto Âncora entende a escola como um espaço de humanização, sendo que a aprendizagem do educando deve se dar por meio da troca de experiências e vivência dos conteúdos. Dessa forma, desenvolvem-se habilidades sociais, críticas e autônomas, que 
visam à formação integral do indivíduo, para que este possa atuar de forma positiva na sociedade (PROJETO ÂNCORA, 2019b).

A organização escolar apresenta a primeira evidência de como as ações do projeto estão voltadas para os educandos, à sociedade e às suas necessidades. Contrariamente, a organização escolar tradicional parte primeiramente dos conteúdos escolares para somente depois de todo o processo voltar a atenção para a criança, o projeto parte das necessidades das crianças e da sociedade, promovendo a aprendizagem a partir dos interesses desta, com métodos de pesquisa que partem do território com espaço de aprendizagem, monitorada por tutores que fornecem os suportes pedagógicos necessários para que a criança tenha condições de planejar e organizar suas aprendizagens, levando assim ao ponto de chegada, qual seja, a aprendizagem dos conteúdos do currículo obrigatório, e a concretização da habilidades cidadãs, de protagonismo e autonomia. A organização do Projeto Âncora é planejada para desenvolver a autonomia da criança em todos os seus níveis; para tanto, a escola não conta com sala de aula, mas com espaços de estudos coletivos. Dessa forma, os educandos são divididos somente pelo grau de sua autonomia em três núcleos, o de iniciação, o de desenvolvimento e o de aprofundamento (PROJETO ÂNCORA, 2019c).

Para que os educandos tenham condições de desenvolver os requisitos propostos pelo Âncora, eles devem dispor de dispositivos que dão suporte à aprendizagem, são eles: i) o planejamento - a criança inicia seu dia planejando as ações que ela pretende realizar, que derivam de um planejamento anterior organizado entre ele e seu tutor, para facilitar e organizar seu aprendizado; ii) a pesquisa - para cumprir com o roteiro de estudos, a criança conta com o auxílio de livros, pesquisas na internet, dos educadores e dos outros educandos que se disponibilizam a ensinar o que já aprenderam, para tal, o educando precisa aprender a coletar informações, organizar e ordenar os seus textos de forma que facilite o compartilhamento do conteúdo com os outros educandos; iii) as oficinas - os educandos podem participar, ou não, de oficinas que buscam ampliar os repertórios da criança; iv) os grupos de responsabilidade - os educandos dividem-se em grupos responsáveis por exercer certas atividades no Âncora, estes grupos surgem a partir da necessidade de resolver certos problemas que aparecem no cotidiano do projeto, e a escolha dos membros de cada grupo de responsabilidade é feita nas assembleias estudantis; v) as assembleias - em reuniões organizadas pelos educandos discutem-se os acontecimentos cotidianos do projeto, promovendo a reflexão e a elaboração de soluções para os conflitos que surgem na comunidade escolar; dessa forma, promove-se a iniciação das crianças como seres políticos atuantes no seu meio social; vi) as rodas de conversa - organizam-se momentos para que 
todos possam se envolver na solução dos acontecimentos escolares, de modo que torne possível que cada um manifeste sua opinião, e entrar em acordo; vii) o brincar - é pelas atividades lúdicas e ativas que ocorrem as aprendizagens significativas da crianças, e é por meio da brincadeira que elas conseguem estabelecer conexões que mais adiante se tornarão parte do seu caráter e das suas ações morais (PROJETO ÂNCORA, 2019c).

A respeito dos valores matriarcais do Âncora, o Projeto Pedagógico determina:

\begin{abstract}
1- Uma equipe coesa e solidária e uma intencionalidade educativa claramente reconhecida e assumida por todos (educandos e educadores) são os principais ingredientes de um projeto capaz de sustentar uma ação educativa coerente e eficaz.

2- A intencionalidade educativa que serve de referencial ao Projeto Pedagógico da Escola Âncora orienta-se no sentido da formação de pessoas e cidadãos cada vez mais cultos, autônomos, responsáveis e democraticamente comprometidos na construção de um destino coletivo e de um projeto de sociedade que potenciem a afirmação das mais nobres e elevadas qualidades de cada ser humano.

3- A Escola não é uma mera soma de parceiros justapostos e atividades ritualizadas - é uma formação social em interação com o meio envolvente e outras formações sociais na qual permanentemente convergem processos de mudança desejada e refletida. [...]

5- A Escola reconhece aos pais o direito indeclinável de escolha do projeto educativo que considerem mais apropriado à formação dos seus filhos e, simultaneamente, outorga-se o direito de propor à sociedade e aos pais interessados o projeto educativo que julgue mais adequado à formação integral dos seus educandos. (PROJETO ÂNCORA, 2011, p. 1).
\end{abstract}

Portanto, o Projeto Âncora visa desenvolver a cidadania na criança, por meio de atividades que possuem como base o princípio da autonomia e da cooperação. Vê-se, pois, que as ações desenhadas pelo projeto destacam as necessidades individuais de aprendizagem das crianças, com o intuito de colaborar para a realização dos projetos de vida de cada educando. Logo, é indiscutível o fato de que a instituição promove, por meio de sua metodologia inovadora, reflexões em seus estudantes, capazes de potencializar as qualidades mais nobres da humanidade. Essa potencialização se dá por meio da afirmação e da consolidação dos valores que norteiam toda a prática pedagógica do projeto, como veremos a seguir.

\title{
4.2 A educação com base em valores .
}

As práticas pedagógicas do Projeto Âncora possuem como objetivo melhorar as capacidades sociais e intelectuais de seus educandos. Para que os seus componentes sociais consigam êxito nas suas relações para eles mesmos e para com os outros, o projeto possui como base cinco valores estabelecidos como essenciais para formar um indivíduo que corresponda às necessidades sociais de sua comunidade (PROJETO ÂNCORA, 2011).

Segundo Almeida (2017), a diferença entre o Projeto Âncora e as escolas tradicionais está nos métodos utilizados pela instituição, devido ao destaque que esta dá à 
construção das bases sentimentais da criança, as atitudes, emoções, condutas e sentimentos; promove uma humanização das relações escolares. Nesse contexto, a afirmação dos valores, por meio das relações cooperativas, é que fazem do projeto uma instituição de destaque no campo das metodologias inovadoras de educação.

Os valores que constituem a base das ações educativas do Projeto Âncora são: honestidade, responsabilidade, afetividade, solidariedade e respeito. $\mathrm{O}$ valor da honestidade baseia-se na relação de confiança estabelecida entre os componentes, por consequência as ações devem ser sempre sinceras, de forma que os indivíduos não percam a confiança que estabeleceram entre si. A responsabilidade é trabalhada por meio dos compromissos que a criança estabelece para consigo e para com os outros, como roteiros e planejamentos de estudos. A afetividade é o valor que orienta as críticas, e posturas dos educandos, este valor é trabalho de forma que busca evidenciar para as crianças que as ações baseadas em bons sentimentos produzem melhores resultados que a humilhação e a crítica depreciativa. A solidariedade é o valor que busca romper com as barreiras que dividem os indivíduos, colocando-os acima do egocentrismo, fazendo-os voltar seus olhares para a necessidade de amparar seus colegas com humildade e carinho quando estes precisarem. O respeito é o valor que orienta toda a prática do Âncora, pois suas metodologias destacam-se pelo respeito à individualidade de cada pessoa, assim as crianças compreendem que a existência de diferenças faz parte da sociedade, mas que, independentemente disso, todos podem ser capazes de assumir suas responsabilidades quando apoiados e respeitados (ALMEIDA, 2017).

O mesmo autor evidencia a importância das relações baseadas em valores para algumas crianças acolhidas pelo Projeto Âncora:

[...] a importância das relações baseadas no respeito, na afetividade,
especialmente para as crianças que demonstram não vivenciar este tipo de relação
fora deste ambiente, as quais, expressam baixa estima, uma profunda descrença
em si mesmas, atitudes hostis e até agressivas, entre outros comportamentos que
denotam existir questões profundas de conflitos emocionais, que refletem em seus
comportamento. Contudo, quando acolhidas nessas expressões, passam a
vivenciar relações de afeto, respeito e solidariedade, percebendo que existem
outros tipos de relações e por mais ou menos tempo que transcorra, vão
transformando-se e manifestando-se de outra forma (ALMEIDA, 2017, p. 110).

Por fim, podemos chegar à conclusão de que quando a escola estabelece como objetivo promover, em seus educandos a internalização de valores, como respeito, honestidade, afetividade, responsabilidade e solidariedade, acaba por gerar no indivíduo características encontradas em cidadãos que cuidam e praticam atos que buscam melhorar 
seu convívio social. Logo, compreende-se que as consequências das metodologias adotadas pelo projeto interferem, de forma positiva, na vida dos seus educandos.

\section{RESULTADOS E DISCUSSÃO}

Este estudo teve como objetivo conhecer o Projeto Âncora a partir das produções acadêmicas e jornalísticas, registrando suas peculiaridades, especialmente as relacionadas aos aspectos metodológicos da educação moral, comparando-os às teorias de prevenção da criminalidade. Supôs-se que uma educação baseada em aspectos da educação moral pudesse ser de grande ajuda na diminuição dos índices criminais.

Isso porque, para Durkheim (1999), uma ação só pode ser considerada criminosa quando ofende os sentimentos gerais e energéticos da consciência coletiva. Ou seja, o autor deixa claro que o crime ocorre porque o indivíduo rompe com a moral da sociedade em que está inserido.

A respeito das teorias da criminalidade, pode-se observar que a maioria das concepções voltadas às percepções do crime, principalmente as teorias consensuais, destaca que, para que a sociedade funcione, seus componentes devem estar em perfeita sintonia, honrando as regras estabelecidas por ela. Dessa forma, o crime só ocorre porque o cidadão não compartilha das normas e valores contidos em sua comunidade. Destaca-se que a ação criminosa pode ser prevenida de três maneiras: a primeira ocorre na raiz das causas dos crimes, como falta de emprego, segurança e precariedade nos serviços educacionais; a segunda, na forma ostensiva representada por ações policiais que procuram diminuir o número de crimes; e a terceira, quando o indivíduo já cometeu atos ilícitos e está sendo punido pelo crime, manifesta-se por meio de promoção de ações que buscam promover a reabilitação do criminoso, para que este tenha condições de voltar a viver em sociedade.

Vale destacar que a prevenção primária, por agir na raiz das causas dos crimes, é a melhor opção quando se trata de manter a estabilidade social, principalmente quando se dá na instituição que mais representa a realidade do convívio social, a escola. Por esse motivo, conforme explicado acima, a prevenção do crime busca promover a manutenção da paz e da harmonia social (PENTEADO FILHO, 2012).

Quanto às teorias de educação moral, percebe-se que, quando baseada em relações de respeito unilateral, moral heterônoma, a educação moral manifesta-se de forma incompleta, pois o respeito dá-se em uma relação de desiguais, em que o menor sente-se obrigado a se submeter às regras do maior; dessa forma, a criança não absorve e pratica as 
morais porque compreende a sua importância, mas, por medo da punição que ele poderá receber, caso não as siga. Nesse caso, a educação moral, para ser realizada de forma plena e eficaz, deve basear-se numa relação de respeito mútuo, moral autônoma, de forma que todos se considerem como iguais e se respeitem reciprocamente, estabelecendo uma relação de cooperação em que um se disponibiliza a ajudar e a entender o outro. Dessa forma, a criança pratica as normas morais não por medo de sanções, mas por compreender e respeitar a sua importância, na formação de uma sociedade mais igualitária. Vale destacar que a educação moral não deve ocorrer somente por meio de lições de morais, mas também, e principalmente, por meio de ações práticas que promovam a reflexão e a internalização das morais sociais.

Seguindo a perspectiva de uma educação causadora de uma moral autônoma, Piaget (1996) destaca que, como a escola é uma sociedade real, deve-se confiar aos integrantes dela a responsabilidade pela organização e funcionamento, a eles deve ser dado o poder de estabelecer as leis escolares, fazer cumpri-las e eleger seus representantes. Dessa forma, a instituição promoveria a adesão voluntária às normas, já que estas foram criadas por eles e não impostas a eles. Ainda na perspectiva emancipadora, o autor defende que a educação moral deve promover ações que valorizem os valores da bondade, do caráter, da verdade, da objetividade, do controle dos instintos, da responsabilidade e da justiça, assim como preparar os indivíduos para serem cidadãos responsáveis por suas ações perante a sociedade.

Sobre as metodologias adotadas pelo Projeto Âncora, percebe-se que a instituição preconiza relações baseadas na interação de seus educandos, de forma que, para fomentar a interação entre os estudantes, a escola não possui sala de aula nem divisões por séries, os educandos são divididos somente por seu grau de autonomia e são os responsáveis pela manutenção da escola em todos os seus mais variados níveis, que vão desde a limpeza até a determinação das normas gerais escolares. Dessa forma, a aprendizagem da criança parte não do conteúdo curricular obrigatório, mas dos interesses que esta manifesta sobre determinados assuntos; assim, para alcançar a sua autonomia, é o estudante quem organiza e planeja o que pretende aprender, exercendo o protagonismo de sua vida. Para alcançar esses objetivos, o projeto apresenta, por exemplo, mecanismos de fortalecimento da autonomia do estudante, como planejamento, pesquisa, oficinas, grupos de responsabilidade, assembleias, rodas de conversa e brincadeiras.

As ações executadas pelo Projeto Âncora procuram desenvolver seres atuantes no seu meio social, que se tornem protagonistas de suas vidas, exercendo suas habilidades de 
cidadãos. Para isso, o projeto deixa claro que todas as suas metodologias possuem como base os cinco valores que o fundamentam, quais sejam: honestidade, responsabilidade, afetividade, solidariedade e respeito. Esses valores são firmados por meio de relações cooperativas, baseadas no respeito mútuo, que acabam por humanizar as relações escolares, permitindo-lhes compreender e absorver as características de um cidadão comprometido com o desenvolvimento de sua comunidade (PROJETO ÂNCORA, 2019).

Devido à necessidade atual de a sociedade buscar meios de diminuir os índices de criminalidade que assolam o Brasil, este estudo buscou compreender algumas possibilidades da prevenção do crime. Observou-se, por exemplo, que, para as teorias, o crime só ocorre porque o indivíduo não está de acordo com as regras morais da sociedade, e para que ele se aposse destas é preciso que elas sejam construídas por meio de relações de respeito mútuo. Essas premissas do respeito às regras, presentes nas relações de respeito mútuo, podem ser encontradas nas práticas educativas do Projeto Âncora, que visa "contribuir à construção de cidadãos conscientes de suas capacidades para coletivamente formar uma sociedade justa, equilibrada e sustentável, a partir de uma prática educacional acolhedora e participativa na construção de Comunidades de Aprendizagem" (PROJETO ÂNCORA, 2019, online).

Diante das informações apresentadas neste estudo, é possível afirmar as metodologias adotadas nas propostas educacionais do Projeto Âncora, que desenvolve em seus educandos o senso de responsabilidade sobre o andamento das questões sociais. Dessa forma, suas práticas educativas criam indivíduos respeitosos, que compreendem a importância das regras sociais na manutenção da sua comunidade, de forma que possuem menos chances de cometer atos que vão contra a consciência coletiva da sociedade, ou seja, possuem menos chances de lutar contra as morais de seu grupo.

\section{CONCLUSÃO}

O presente estudo possibilitou compreender que investir na moral, na área de educação escolar, pode ser de grande valia na prevenção primária da criminalidade. Fica evidente, diante das informações apresentadas neste texto, que o crime é um ato de desrespeito às normas da sociedade, sejam jurídicas ou morais, e nem sempre se pune de forma merecida. Quando a consciência coletiva é atingida, é necessário que ela resista e reafirme sua onipotência, procurando punir o autor da agressão, de forma a fazer este servir de exemplo para que outros não ocorram, e que a consciência coletiva permaneça estável. A 
prevenção criminal é de suma importância para garantir o funcionamento regular das sociedades. Compreende-se que a prática de crimes não é uma doença, e que a sociedade é quem precisa encontrar meios para solucionar o problema que a aflige. Partindo dessa premissa, as seções a seguir terão como base a prevenção primária da criminalidade, com foco na educação. De modo geral, destaca-se que uma educação, baseada no respeito mútuo e em ações cooperativas, proporciona a internalização das morais sociais, fazendo com que os educandos sejam menos propensos a práticas de crimes. Pode-se dizer que as iniciativas do Projeto Âncora promoveram grandes agitações no mundo acadêmico e educacional brasileiro. Devido às suas metodologias inovadoras, o projeto ganhou atenção internacional e tem sido objeto de diversas pesquisas acadêmicas que procuram entender seu funcionamento, suas consequências e possíveis colaborações para a sociedade brasileira, como é o caso deste presente trabalho. A atenção dada nesta pesquisa à educação moral realizada na escola não tem por objetivo colocá-la acima dos outros métodos de prevenção do crime, mas apenas evidenciá-la como uma possibilidade de investimento para a contenção da criminalidade. Caso seja de interesse da sociedade, aconselha-se a promoção de pesquisas quantitativas que busquem diagnosticar o grau de intervenção que as práticas educativas do Projeto Âncora podem gerar na criação de um indivíduo autônomo e responsável.

\section{REFERÊNCIAS}

ALMEIDA, Sheyla Gomes de. Projeto Âncora: uma perspectiva de educação para a integralidade humana. 2017. 235p. Dissertação (Mestrado em Educação) - Universidade de Brasília. Brasília, DF, 2017.

ÀLVAREZ, Pilar.No presídio das mulheres que abo rtam. El País. Izalco - El Salvador, 11 de Jun de 2019. Disponível em

$<$ https://brasil.elpais.com/brasil/2019/06/07/internacional/1559897480 579395.html>

Acesso em: 11 jun. 2019.

BRASIL. Constituição (1988). Constituição da República Federativa do Brasil. Brasília, DF: Senado Federal: Centro Gráfico, 1988, 292 p.

CALHAU, Lélio Braga. Resumo de criminologia. $2^{\circ}$ ed. Niterói: Impetus, 2009. 119p. Disponível em: <http://arquimedes.adv.br/livros100/Resumo\%20de $\% 20$ Criminologia $\% 20$ \%20L\%C3\%A9lio\%20Braga\%20Calhau.pdf> Acesso em: 10 jun. 2019.

DORNELLES, João Ricardo W. O que é Crime. $1^{\circ}$ e-book. São Paulo: Brasiliense, 2017. 59p. Disponível em: $<$ https://books.google.com.br/books?id=EmkvDwAAQBAJ\&printsec $=$ frontcover\&dq $=0+q$ ue $+\%$ C3\%A9+crime\&hl $=$ pt- 
BR\&sa $=$ X\&ved=0ahUKEwiojvjMmuTiAhXdDrkGHStjA6IQ6AEIKTAA\#v=onepage $\& q=$ o\%20que $\% 20 \%$ C3\%A9\%20 crime \&f=false $>$ Acesso em: 6 jun. 2019.

DURKHEIM, Emile. Da divisão do trabalho social. Tradução: Eduardo Brandão. 2. ed. São Paulo: Martins Fontes, 1999. 483p.

FóRUM BRASILEIRO DE SEGURANÇA PÚBLICA. Anuário Brasileiro De Segurança Pública 2018. São Paulo, 2018. 90p. Disponível em:

$\mathrm{http} / / / \mathrm{www}$.forumseguranca.org.br/publicacoes/anuario-brasileiro-de-seguranca-publica2018/. Acesso em: 5 jun. 2019.

GALVÃO, Fernando. Direito Penal Curso Completo. $2^{\circ}$ ed. Belo Horizonte: Del Rei, 2007. 951p. Disponível em:

$<$ https://books.google.com.br/books?id=z50121BjM0QC\&printsec=frontcover\&dq=direito + penal ++ curso + completo\&hl $=$ pt-

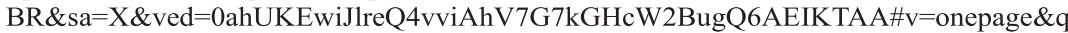
$=$ direito $\% 20$ penal $\% 20 \% 20$ curso $\% 20$ completo $\& \mathrm{f}=$ false $>$ Acesso em: 10 jun. 2019.

LA TAILLE, Yves de. Moral e ética: dimensões intelectuais e afetivas. Porto Alegre: Artmed, 2006. 150p.

PENTEADO FILHO, Nestor S. Manual esquemático de criminologia. $9^{\circ}$ e-book. São Paulo: Saraiva, 2018.

PIAGET, Jean. O Juízo Moral na Criança. Tradução: ElzonLeoonardon.4 ed. São Paulo: Summus, 1994. 302p.

PIAGET, Jean.. Os Procedimentos da Educação Moral. In: MACEDO, Lino de. Cinco estudos de educação moral. São Paulo: Casa do Psicólogo, 1996. Disponível em: $<\mathrm{http}: / /$ materiadeapoioaotcc.pbworks.com/f/Jean+Piaget++Os + procedimentos + da + Educa $\%$ C3\%A7\%C3\%A3o+Moral.pdf> Acesso em: 12 jun. 2019.

PIAGET, Jean.Para onde vai a educação? Tradução: Ivete Braga. $22^{\circ}$ ed. Rio de Janeiro: José Olimpio, 2015. 127p.

PROJETO ÂNCORA. História. Disponível em:

$<$ https://www.projetoancora.org.br/historia $>$ Acesso em: 19 jun. 2019a.

PROJETO ÂNCORA. Estrutura. Disponível em:

$<$ https://www.projetoancora.org.br/estrutura> Acesso em: 19 jun. $2019 \mathrm{~b}$.

PROJETO ÂNCORA. Pedagogia. Disponível em:

$<$ https://www.projetoancora.org.br/pedagogia >Acesso em: 19 jun. 2019c.

PROJETO ÂNCORA. Estatuto social. Cotia: 2016. 11p. Disponível em:

$<$ https://drive.google.com/file/d/0B0YJb0CKg4u1ZDZzelpYQjNCblU/view > Acesso em: 19 jun. 2019.

PROJETO ÂNCORA. Projeto Pedagógico. Cotia: 2011. Disponível em: $<$ https://drive.google.com/file/d/1Ns8VwmlS4Z-QSUbX6ZqAeNeNXmn23zH2/view> Acesso em: 19 jun. 2019.

Recebido em: 20/04/2020

Aprovado em: 13/05/2020 